\title{
Properties of Technical Systems - Key to Crossing Design Boundaries
}

\author{
W. Ernst Eder
}

\begin{abstract}
Based on a model of a transformation system, a complete set of classes of properties for all products is developed.

The design specification should give a clear statement of the requirements for the product.

Various kinds of product can be recognized. Consequently three typical design processes are: design engineering, industrial design, and integrated product development.

For a design process, the proposed set of classes of properties provides a good guideline or heuristic for setting up a design specification. This set of classes of properties supports a directed creativity. It indicates where expertise is needed to obtain an optimal designed product.
\end{abstract}

\section{Introduction}

One of the problems of investigations into design engineering has been to separate an Engineering Design Science from any proposed or discovered procedure or method for designing. This separation has not been consistently applied, but is essential for understanding both the theory (science) and the prescribed method.

Three procedures for designing are generally recognized, design engineering, industrial design, and integrated product development. Whilst these three procedures show regions of overlap with respect to the sorts of product for which they are suitable, there are substantial regions where only one or two of them apply.

A science (from Latin 'scientia' - having knowledge); has the task to produce and verify knowledge, independent of its potential use, to isolate and study (reproducible) phenomena, abstract and codify from available and observed information. The main aim of science is to study what exists, and to try to explain it in a generally agreed way, by deductive logic, but also by induction, abduction and reduction, and innoduction [Eekels 2000] This understanding should then be synthesized into a more holistic view. Science should thus be as purely descriptive as possible, but also logical and complete - producing a descriptive theory. Each region of science deals with only a small range of phenomena - and over time the range of each science tends to narrow as further specialized sciences arise.

The subject of our investigation is design engineering, both its procedures and its results. The science of design engineering, Engineering Design Science [Hubka 1988, 1992 and 1996] should be articulated to be as independent as possible from the actual methods and procedures used during designing.

Quoting Klaus [1965]: 'Both method and theory emerge from the phenomenon of the subject'. Figure 1 indicates that close relationships should exist between the subject under consideration (its nature as a concept, product, artifact or process), the basic theory (formal or informal, recorded or in a human mind), and the recommended method. The theory should describe and provide a foundation for the behavior of the (natural or artificial, tangible or process) object, i.e. it should answer the questions of 'why,' 'when,' 'where,' 'how' (with what means), 'who' (for whom and by whom), with adequate and sufficient precision. The theory should also support the utilized methods, i.e. answer the questions of 'how' (procedure), 'to what' (subject), both for using and/or operating the subject, and for designing the subject. The method should also be sufficiently well adapted to the subject, its 'what' (existence), and 'for what' (its anticipated and actual purpose). These three phenomena of theory, method and subject are of equivalent status to each other. The questioning used here is closely related to the 'six W work-study questions' recommended by F.W. Taylor [1919], and (in an expanded form) declared by Aristotle [384-322 BCE] in his 'Topica'. Figure 1 also shows that a theory is usually developed from the phenomenon of the subject, and that a coordinated method can then be formulated. Nevertheless, both theory and method can be bypassed in intuitive leaps that can sometimes be rationalized after the event. 


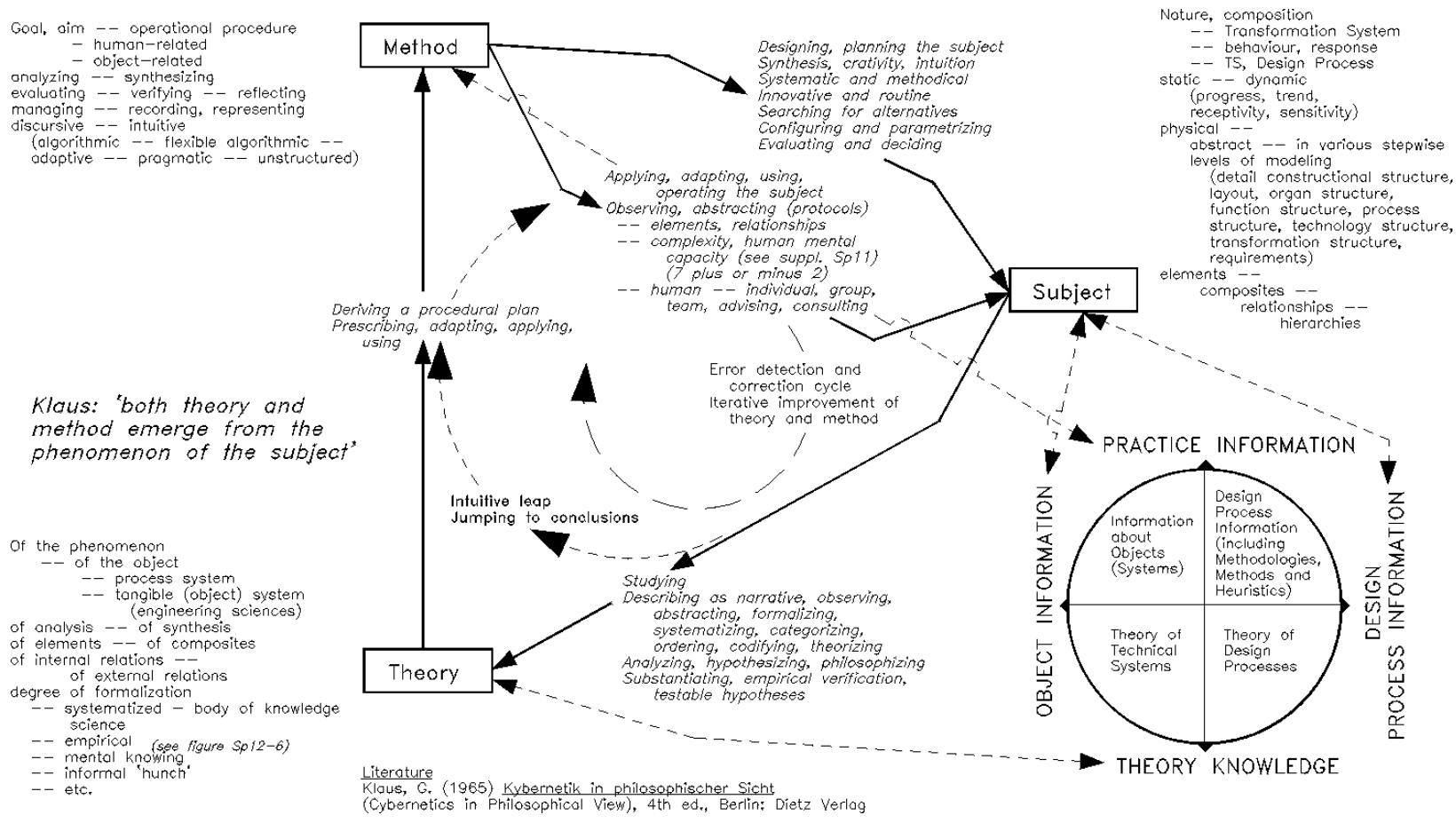

Figure 1. Relationships Among Subject, Theory and Method

\section{Model of Transformation System}

A basic model of Engineering Design Science is that of the transformation system, see figure 2. This model declares:

- An operand (materials, energy, information, and/or living things $-\mathrm{M}, \mathrm{E}, \mathrm{I}, \mathrm{L}$ ) in state Od1 is transformed into state $\mathrm{Od} 2$, using the active and reactive effects (in the form of materials, energy and/or information - M, E, I) exerted (as outputs from their internal processes) by the operators (human systems, technical systems, active and reactive environment, information systems, and management systems), by applying a suitable technology (which mediates the exchange of $\mathrm{M}$, E, I between operand and effects), whereby assisting inputs are needed, and secondary inputs and outputs can occur for the operand and for the operators.

For any typical technical system TS(s) as subject of our interest, the life cycle consists of a sequence of transformation processes, each driven by its own operators, as shown in figure 3 . This is the minimum number of life-cycle phases that provides complete coverage, and is as general as possible. Each of these typical life-cycle phases is usually composed of many

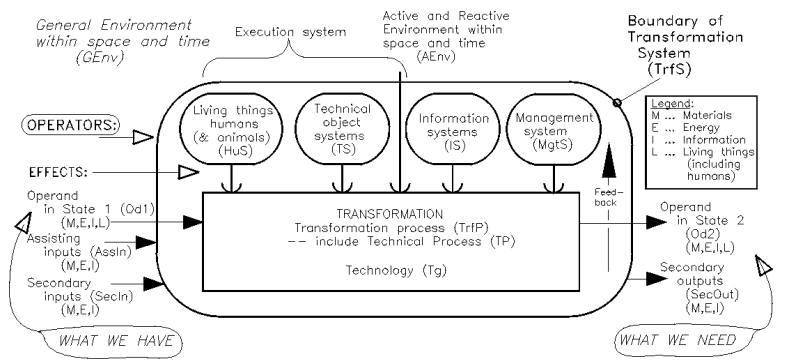

\section{Figure 2. General Model of a Transformation System}

transformations, but these can no longer be specified in the general way demanded by Engineering Design Science.

In the first three of these typical life-cycle phases, LC1 - LC3, the TS(s) exists only as information. A tangible form of the TS(s) exists in the other phases, LC4 - LC7, together with the information content of that particular tangible form as designed and manufactured.

The scope of Engineering Design Science can be summarized in a map, figure 4 , in which theory knowledge is located in the 'south', information about practical advice and application is located in the 'north', information about existing tangible objects and processes in the 'west', and information about 


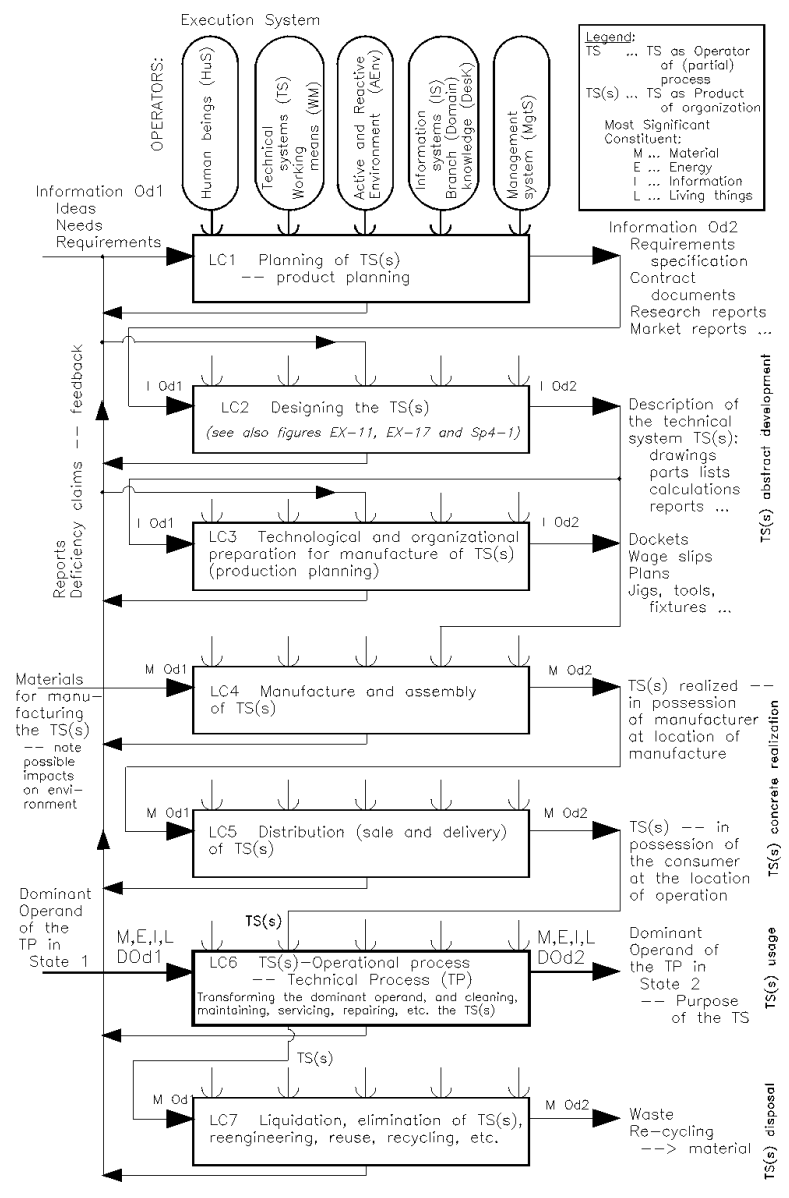

Figure 3. Life Cycle of a Technical System

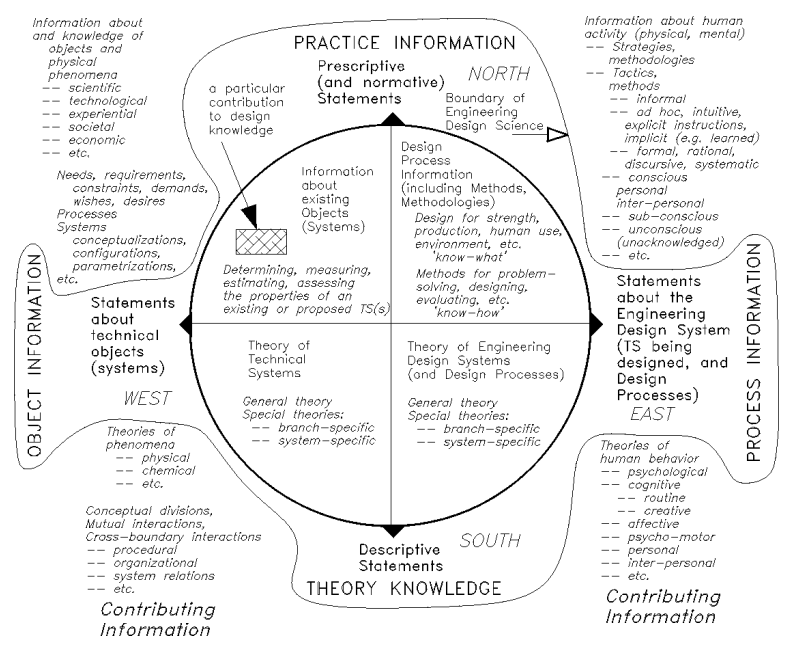

Figure 3. Map of Engineering Design Science and its Context

design processes and their heuristics and methods in the 'east'.

\section{Some Implications for Method}

One implication from figure 1 is that if we know a theory of the subject, we should be able to derive a prescription of a method. Using the convention suggested by Koen [2003]: a method is a prescription for anticipated future action, for which it is heuristically imperative that you adapt it flexibly to your current (ever changing) situation, where the underscore under the second letter of a word indicates its heuristic nature - and nearly all words in this paper should have their second letters underscored. Every practice (as subject) can benefit from a wellformulated theory to explain it in generalized terms. Then, the triad of 'subject -- theory - method' can help towards using and/or designing the subject.

During the actual life cycle of a TS(s), figure 3, the nature of the procedures for phases LC1 $-\mathrm{LC} 3$ is that the TS(s) exists as information. This information is progressively concretized (synthesized) until we have a full description of the TS(s) ready for manufacture and/or implementation. The documentation of LC1 LC3 should contain records of all alternative solution proposals that were considered. The full description of the TS(s) contains only the information about the TS(s) to be manufactured and/or implemented. The TS(s) cannot carry information about any other alternatives that were considered during life-cycle phases LC1 - LC3.

Nevertheless, this final description should contain all necessary considerations about needs and influences from the operators in the tangible life-cycle processes for future TS(s), LC4 - LC7. As shown in figure 3 , the information as output from life-cycle phases LC1 - LC3 acts as one of the five operators of phases LC4 onwards, and therefore already contains the effects of operators of LC1 - LC3, as considered during those origination phases.

\section{Theory of properties}

Each technical system TS(s) carries all properties, whether they have been deliberately designed (considered) or whether they arise incidentally or accidentally during designing. The postulated classes of properties should be theoretically complete and exhaustive.

According to Smith [2005], see figure 5:

(1) Properties Define Entities: properties are behavioural characteristics that an entity possesses. Since only this behaviour is used, properties completely define entities. 
(2) Relationships Require Properties: for relationships to make use of behaviour, the entity must have that behavioural characteristic or property.

(3) Relationships Constrain Entities: relationships in some way constrain the use of entities since each entity must maintain certain relationships with other entities. It is through relationships that the use of entities is bounded.

In our case, the entities are either transformation processes, or technical systems, see figure 2 .

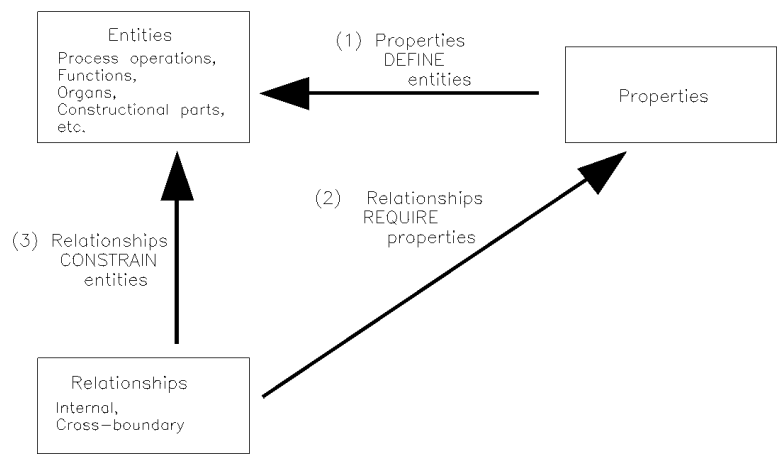

\section{Figure 5. Group Entities and Links for an Existing System}

Classes of properties for a transformation process (TrfP), see figure 2, consist of (a) the properties of the operand, in state Od1, Od2, and in each intermediate state, (b) the properties of any assisting and secondary inputs, (c) the properties of secondary outputs, (d) the types of transformations or operations that are performed on an operand, and (e) the active and reactive effects exerted by the operators that cause the transformation of the operand by means of an applied technology.

As shown in figure 6, the primary class of properties of technical systems should relate to the TS(s) as operator of its operational process (LC6), i.e its usage for its intended purpose - we will label this as class Pr1. Further classes of TS-properties are needed for the other life-cycle processes where a tangible TS(s) exists - classes Pr2 - Pr4. Figure 6 shows the derivation of classes of TS-properties to provide a complete coverage of all external properties, resulting in a matrix of considerations for operators of those life-cycle processes - classes $\operatorname{Pr} 5$ - Pr9. Subclasses are needed or useful in several of these TSproperty classes to clarify the context of the life cycle, its operators, and especially its active and reactive environment, e.g. management. In addition, three axiomatic classes (Pr10, Pr11 and Pr12) of internal properties (also called design properties) are needed. These are the properties that an engineering designer has under his/her direct control, and with which he/she should realize the required external properties of the future TS(s). These twelve classes constitute a minimum set to provide complete coverage, and to be as general as possible.

The class of internal properties is sub-divided into Pr10 design characteristics, Pr11 general design properties, and Pr12 elemental design properties. The design characteristics and the elemental design properties are causally responsible for the manifestations and values of the general design properties. The elemental design properties include the elements and relationships among them, i.e. the structures of technical systems at various levels of abstraction: function structure, organ structure and constructional structure. It appears therefore that the TS-structures are a sub-set of the TS-properties.

Figures 7 shows a complete listing of the resulting set of TS-properties. The primary properties constitute the theoretically necessary set, the secondary properties (with added identification letter) are subsets arranged according to axiomatic or other considerations. Figure 8 shows the distinction between internal and external properties, Figure 9 indicates that the relationships among the (classes of) properties are complex, a one-to-one relationship rarely exists.

\section{Application of TS-properties}

We also acknowledge a difference between 'determining' and 'establishing' a property. Once a tangible TS(s) exists, even if only as an incomplete collection of constructional parts, various properties can be determined by measuring, simulating or assessing. Before a tangible TS(s) exists, we need to establish the needed internal properties, to predict in advance what manifestations and values may be possible and useful, how to achieve them by the internal design properties.

Technical systems are always created and manufactured for a specific purpose. A need exists, and is usually expressed as a set of requirements for a selection of external properties.

According to Smith [2005]:

(4) Properties Become Requirements: groups can be combined into hierarchies and a property in a parent group is converted into a requirement in a child group.

(5) Relationships Resolve Requirements: relationships make use of the entity behaviour to resolve requirements, such that each requirement is assigned to at least one relationship, and each relationship is assigned to at least one requirement.

(6) Properties Maintain Relationships to Resolve Requirements: properties indirectly resolve 


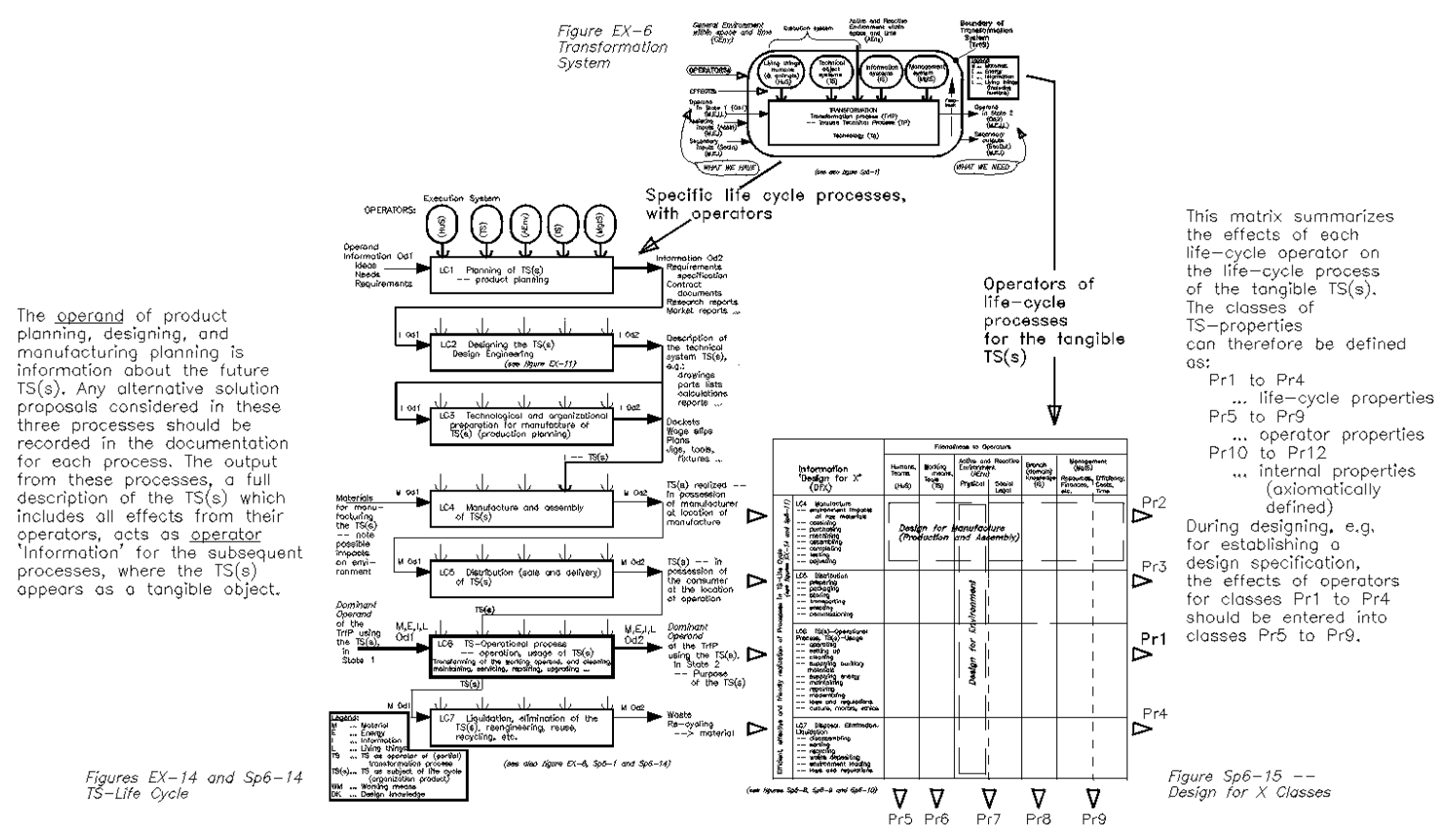

Figure 6. Derivation of Classes of Properties of Technical Systems

requirements by maintaining the relationships that directly resolve requirements. Thus the property maintains a relationship such that the relationship can resolve a requirement. To determine what properties an entity must have, one must combine its relationships with their requirements.

Together with the statements from Smith [2005] in section 4 of this paper, figure 10 shows the complete set of links among these concepts.

In general, the external properties (classes Pr1$\operatorname{Pr} 9$ ) of a future TS(s) cannot be designed directly, except for esthetic and ergonomic properties, which are generally covered by industrial design. For all other external properties (especially class Pr1), the designers directly establish suitable internal properties (classes $\operatorname{Pr} 10-\operatorname{Pr} 12$ ), anticipating that suitable external properties will result.

For the engineering designers, there is therefore a need to set targets, to list all requirements. This should occur from the point of view of management, taking all legal aspects into account. It should also occur from the viewpoint of the engineering designers - a design specification, which can best be established by using the first nine classes of TSproperties, Pr1-Pr9, as shown above (and including aspects of classes $\operatorname{Pr} 10, \operatorname{Pr} 11$ and $\operatorname{Pr} 12$ if needed). This is the recommended method based on the theory of the subject of TS-properties. Its application to a design specification is demonstrated in the case studies of [Eder 2005, 2006, Heffernan 2006].
The relationships among properties (including their manifestations and values) are complex. Most of the external properties interact with each other, as shown in figure 9, the 'roof' over the left section. Most internal properties interact with each other, as shown in figure 9, the upper 'roof'. In addition, there are complex interactions between external and internal properties, the inner rectangular matrix. Each property influences several other properties.

The TS-structures indicated in the elemental design properties may be used to provide several stages of mappings with recommended methods to generate solution proposals and establish the accepted solution, the TS(s). This systematic and methodical procedure is illustrated in case studies.

\section{Products and Design Processes}

Those artifacts that appear as outputs of enterprise processes and that are intended to provide the operating revenue are often given the designation of 'product', see [ISO9000:2000], which may include processed natural items usually labeled 'produce'. This includes all goods and services offered on the market. Among the almost countless artifacts (enterprise products), we will restrict consideration to those that have a substantial engineering content. These will include both hardware and software products, as well as processes and services. We do not intend to cover non-engineering artifacts, but we suspect that many of the considerations will apply. 


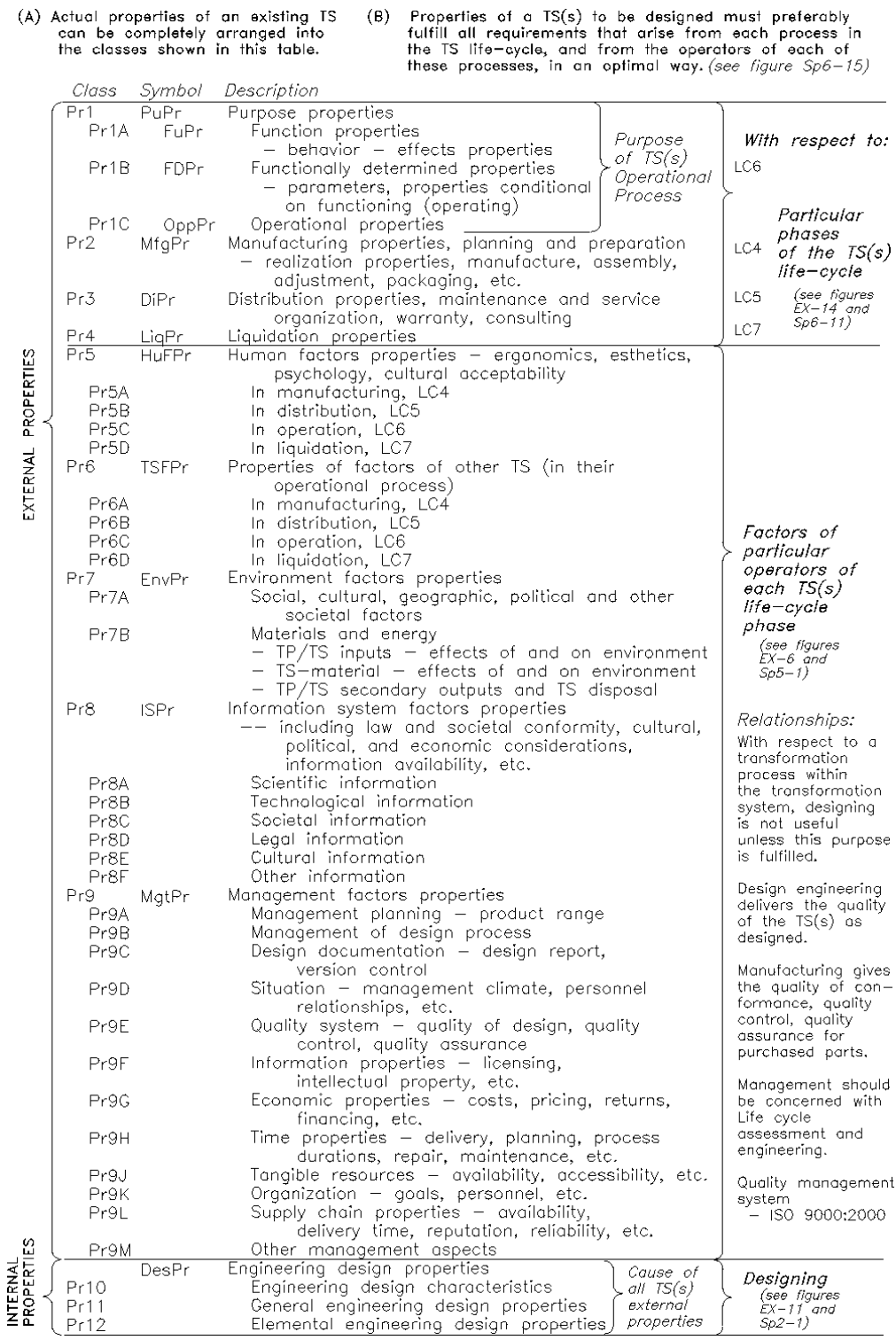

Figure 7. Classes of Properties of Technical Systems

The descriptions offered in this section are intended to provide a rough scale to differentiate artifacts (products) and design processes for the following discussions [Eder 2003]. Individual artifacts may appear in more that one classification, or cross the boundaries. Obviously, a product from one enterprise may be input material for another, e.g. as OEM items (including industrial products).

For artistic works, the artist is usually designer and manufacturer. Appearance is the primary property, esteem value (beauty in the eyes of the beholder) tends to be high compared to costs.

Consumer products are frequently consumable items and materials. Designing involves to some extent the product, but of probably more importance is designing the packaging and advertising (somewhat artistic works).

Consumer durables must have appropriate appearance and operability. They must project the 'right' image of the product and of the manufacturing (or selling) enterprise. These products must also perform useful tasks, they must function with suitable performance parameters - they are technical systems, and can be made available at a suitable cost.

Bulk or continuous engineering products act generally as raw materials for other manufacture (e.g. in other enterprises), e.g., bulk lubricating oils, fuels, metal rolled sections, water piped into homes, etc. 


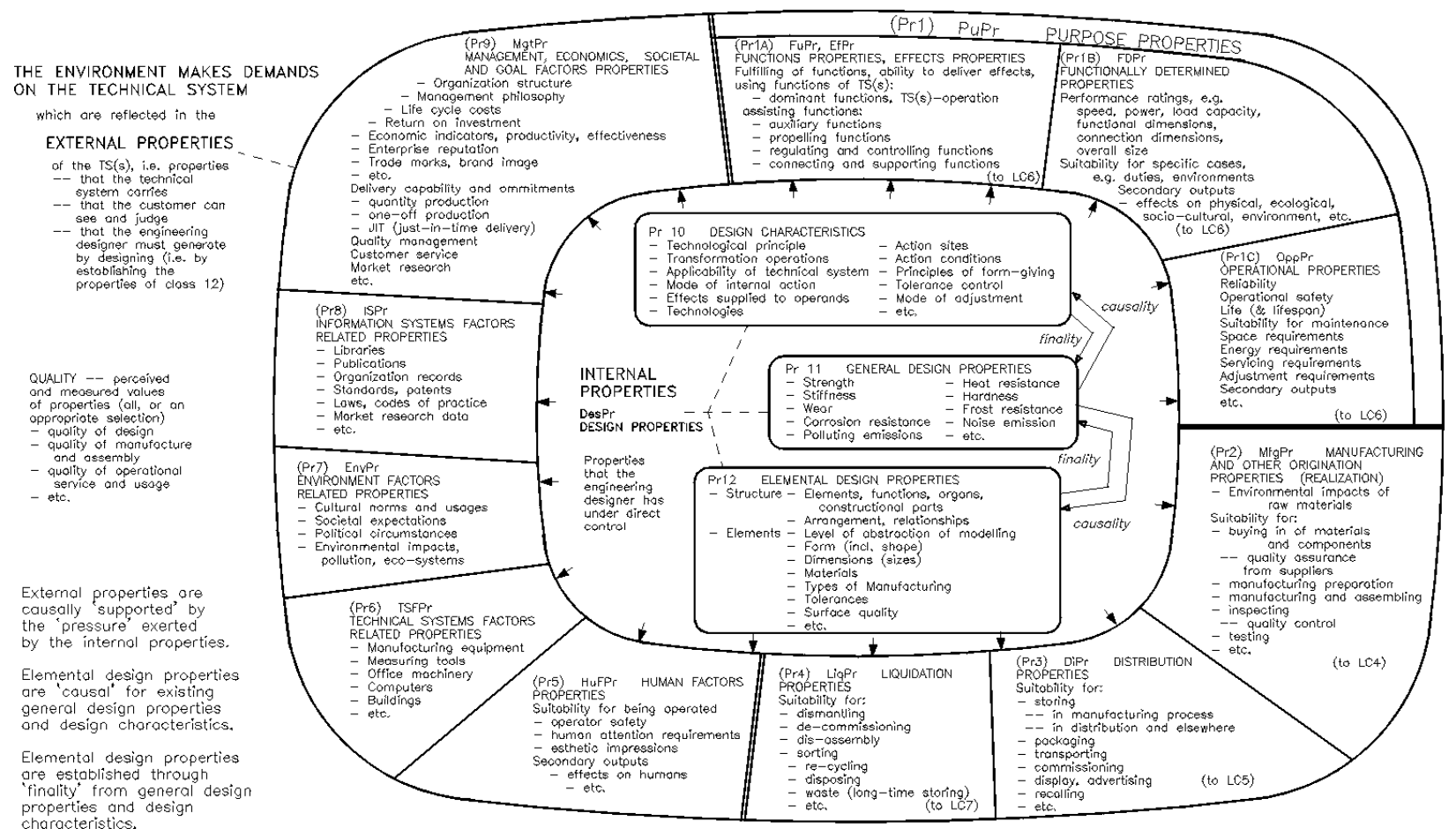

Figure 8. Classes of Properties of Technical Systems
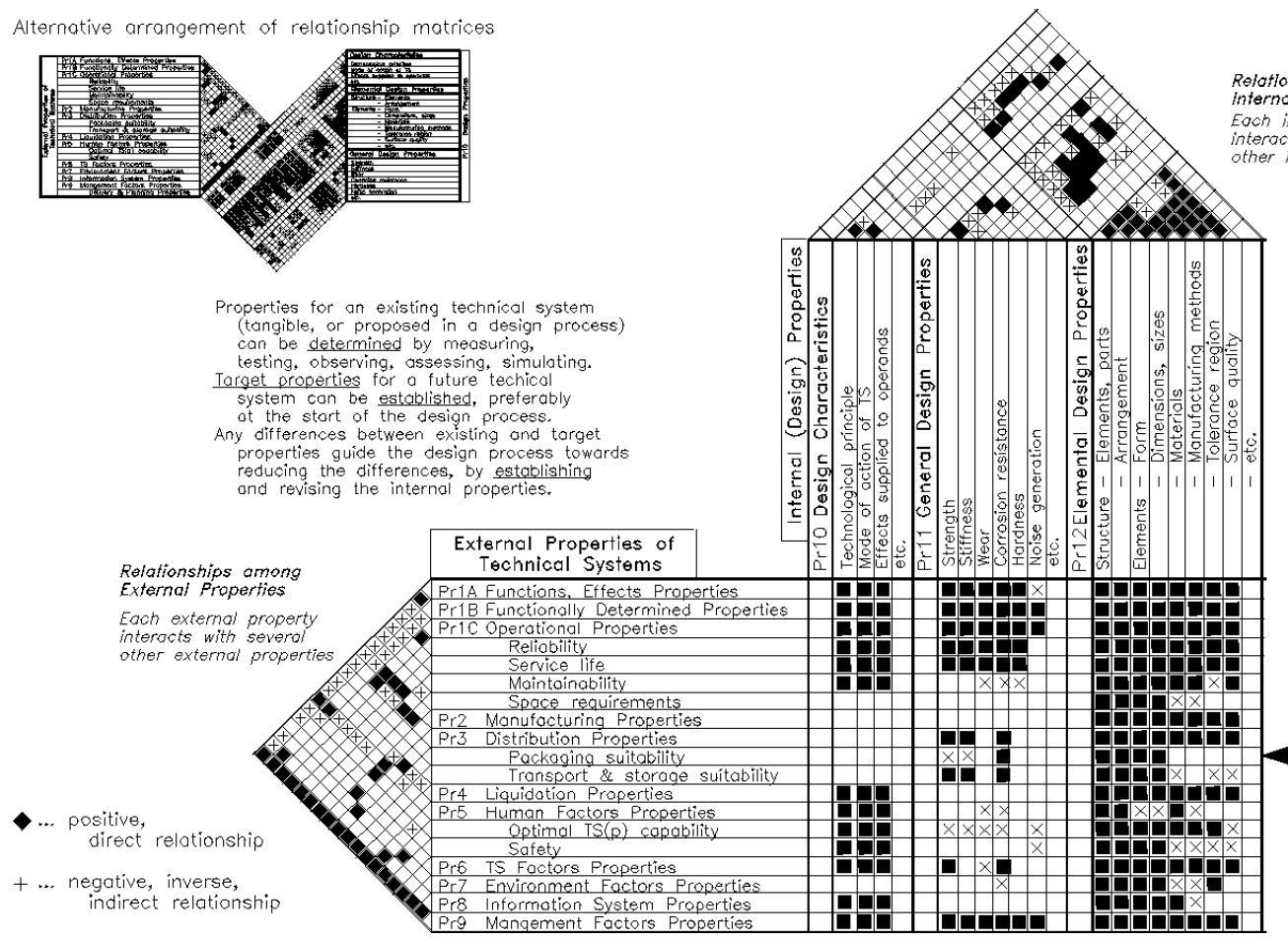

Relafionships batween the dosses of External Properties Properties

Each internol property influences each external property is influenced by several internal properties. Re/ationships between external and internol properties are complex and

Contents of this row: (elements and relationships) of a particular 'Design for $X$ ' class (e+g. suitability for packaging) (see figurs $S_{p 6} 6-15$ )

Figure 9. Example figure 


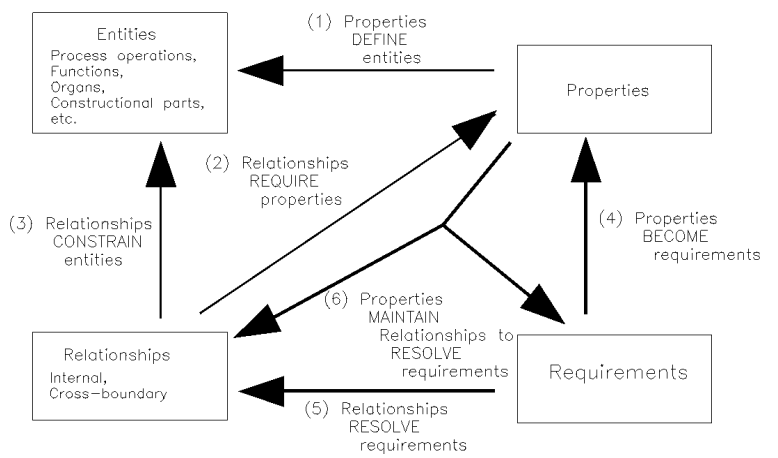

Figure 10. Group Entities and Links for a Required New Technical System

Industry products are generally items or assemblies that are bought by a manufacturing company for assembling into their own products. They include machine elements, purchased OEM goods (products intended for 'original equipment manufacturers' to build into their own devices), COTS (commercial off-the-shelf products), and other hardware (i.e. technical systems, usually of lower levels of complexity), and software.

Industrial equipment products are self-contained devices (e.g. technical systems, machines) which can perform a more or less complex function, and are intended for use within industry.

Special purpose equipment, including jigs, tooling, fixtures, and specialized manufacturing and assembly machinery, special-purpose robotics, handling and packaging machinery, but also ocean-going ships. These technical systems are usually produced to special order ('made to order'), as single items ('oneof-a-kind', 'one-off') or a small series.

Industrial plant usually consists of collections of industrial equipment products, and devices to provide control and/or connections among them - i.e. technical systems.

Configuration products are items of special purpose equipment and/or industrial plant for which the components are quantity-produced and standardized industrial equipment products (OEM, COTS) - designed as modular inter-changeable technical systems (constructional parts for products).

Intangible products are typically documents such as contracts, insurance policies, etc.

A general procedure for creating products of engineering and business consists of planning, LC1, (sometimes issuing a contract), designing (of an enterprise product and its operational process), LC2, manufacturing planning (designing of maufacturing processes), LC3, manufacturing, distributing, using, disposing. Typical paradigms are often quoted, e.g. Life Cycle Engineering, and Integrated Product Development.
Designing, establishing in principle and in detail, in advance, what needs to be made or implemented to achieve that product, for all its life phases, can be sub-divided into

(a) industrial design, establishing the appropriate appearance, ergonomic properties, and economics, with emphasis on customer appeal and satisfaction; and

(b) design engineering, establishing the ways in which the product will function, the constructional parts of which it will be made, as well as influencing all other properties of the product [Eder 2003].

By including a substantial management component, a procedure of integrated product development can be identified. Figure 11 indicates that industrial design, design engineering, and integrated product development do not coincide, each has its own scope and procedures.

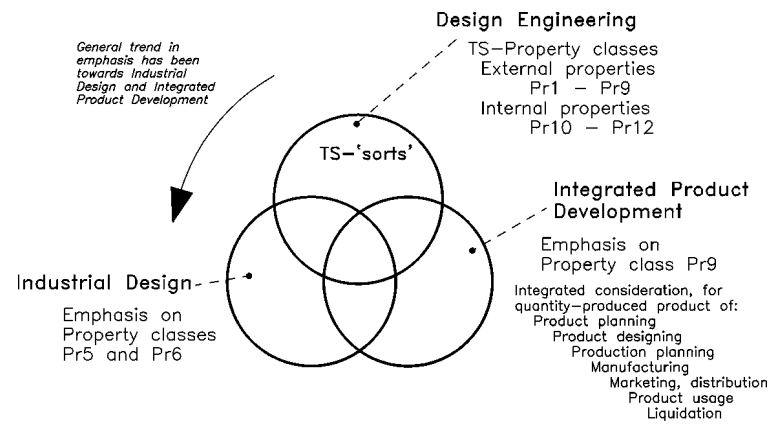

\section{Figure 11. Scope of Sorts of Designing}

The need for planning at various levels of the lifecycle of technical systems (see figure 3), especially in phases LC1 - LC3 should now be obvious. This is the reason for developing 'integrated product development' as the most suitable procedure for quantity-manufactured products. Using the classes of properties as guideline for establishing a design specification, all aspects of the needs and preferences of potential users, stakeholders, collaborators, and influenced persons can be included. These stakeholders (etc.) are in fact mainly the human operators of each of the typical life-cycle processes, LC1-LC7, figure 3.

Appropriate statements of requirements, including values and tolerances, can and should be listed in each class of properties. Each requirement may influence one or several classes of properties. Nevertheless, any value should only appear in one class, to allow easy and reliable changes in the design specification as needed. All other entries of that requirement should cross-reference the valuecontaining statement. As a tool or method for 
designing, this set of classes of properties supports a directed creativity [Eder 1996], allowing an extended search for solution proposals. It also indicates where additional expertise is needed to coordinate the specialists, and thereby to obtain an optimal designed product. The evaluation criteria for any proposed solution can be derived directly from the design specification.

\section{Closure}

The complexity of design engineering resides in the relationships among properties of technical systems. Engineering designers directly establish the internal properties of a technical system to be designed, in order to indirectly establish its external properties. Therefore there is a need for design engineering personnel to know about TS-properties, both in their theory, and in their application.

\section{References}

Aristotle (384-322a BCE) Organon section Topika Eder, W.E. (ed) (1996) WDK 24 - EDC - Engineering Design and Creativity - Proceedings of the Workshop EDC, Zürich: Heurista

Eder, W.E. (2003) 'A Typology of Designs and Designing', in DS 31 - Proc. ICED 03 Stockholm, p. 251-252 (Executive Summary), full paper number 1004 on CD-ROM, The Design Society

Eder, W.E. (2005) 'Application of Design Methodology for Education' in Proc. Second CDEN International Conference, University of Calgary, Alberta, 18-19 July 2005 at Kananaskis Resort, paper 10007 on CDROM

Eder, W.E. (2006) 'Case Study of Design Engineering' in Proc. Third CDEN International Conference, University of Toronto, 24-26 July 2006, paper 10028 on CD-ROM

Heffernan, P. and Eder, W.E. (2006) 'Redesign an Oil Pump - Model Solution to a Student Problem' in, Proc. Third CDEN International Conference, University of Toronto, 24-26 July 2006paper 10044 on CD-ROM

Eekels, J. (2000) 'On the fundamentals of engineering design science: The geography of engineering design science. Part 1', Journal of Engineering Design, Vol. 11, Nr. 4, pp. 377-397 (Part 2 is in Vol. 12, Nr. 3, 2001, pp. 255-281)

Hubka, V., and Eder, W.E. (1988) Theory of Technical Systems, New York: Springer-Verlag

Hubka, V. and Eder, W.E. (1992) Einführung in die Konstruktionswissenschaft (Introduction to Design Science), Berlin, Springer-Verlag

Hubka, V., and Eder, W.E. (1996) Design Science: Introduction to the Needs, Scope and Organization of Engineering Design Knowledge, London: Springer-Verlag, http://deseng.ryerson.ca/DesignScience/
ISO 9000:2000 ISO 9000 Quality Management Systems - Fundamentals and Vocabulary, Geneva: ISO

Klaus, G. (1965) Kybernetik in philosophischer Sicht (Cybernetics in Philosophical View) 4th ed., Berlin: Dietz Verlag

Koen, B.V. (2003) Discussion of The Method: Conducting the Engineer's Approach to Problem Solving, New York: Oxford Univ. Press

Smith, J. \& Clarkson, P.J. (2005) 'Design Concept Modelling to Improve Reliability', Jnl. Eng. Design, Vol. 16, Mo. 5, Oct, p. 473-492

Taylor, F.W. (1919) Principles of Scientific Management, New York: Harper

W. Ernst Eder, MSc, PEng

Professor Emeritus, Dr.h.c. (University of West Bohemia in Pilsen, Czech Republic)

Royal Military College of Canada, Department of Mechanical Engineering

Home Address: 107 Rideau Street, Kingston, Ontario, Canada K7K 7B2

Phone: $\mathrm{x}-1-613-547-5872$

Email: eder-e@rmc.ca 